\title{
Thiazolium and imidazolium cations from ionic liquids as pre-catalysts in benzoin condensation-a mini review
}

\begin{abstract}
Synthesis of benzoins and their substituted derivatives is well known for more than a century since the original work of Liebig and Wöhler. This important strategy to create new $\mathrm{C}-\mathrm{C}$ bonds now uses $\mathrm{N}$-heterocyclic carbenes $(\mathrm{NHC})$ as catalysts, mainly derived from azolium cations obtained from different ionic liquids. Although numerous reports have been published to date, this article covers just the main aspects in the NHC formation from azolium pre-catalysts.
\end{abstract}

Keywords: benzoin condensation, N-heterocyclic carbene, Breslow intermediate, imidazolium and thiazolium salts
Volume 7 Issue 4 - 2018

Andrés-Felipe Villamizar-Mogotocoro, JuanManuel Urbina-González

Escuela de Química, Universidad Industrial de Santander, Colombia

Correspondence: Juan-Manuel Urbina-G., Escuela de Química, Universidad Industrial de Santander, Carrera 27 Calle 9, Ciudad Universitaria, 680002, Bucaramanga, Colombia, Tel +57 7 6349069,Email jurbina@uis.edu.co

Received: July 26, 2017| Published: August 15, 2018

\section{Introduction}

Ionic liquids have been used as a green alternative to the most common organic solvents; $;^{1,2}$ among the most used ionic liquids, those derived mainly from $N, N^{\prime}$-dialkylimidazolium and thiazolium cations have shown their importance also when they are used as $\mathrm{N}$-heterocyclic carbenes (NHC) catalysts in different types of reactions, ${ }^{3-5} e . g$. the "umpolung" (dipole inversion) reaction towards the benzoin condensation, ${ }^{6}$ previously prepared using sodium and potassium cyanides as catalysts; ${ }^{7}$ in 1943 this $\mathrm{C}-\mathrm{C}$ coupling was reported to work with diverse thiazolium salts, ${ }^{8}$ a widely used reaction that nowadays employs thiamine as a safer agent in the undergraduate benzoin preparation laboratory experiment, ${ }^{9}$ in spite of its lower stability in comparison with imidazolium cations against air oxidation in presence of base. ${ }^{10}$ Initial studies about benzoin condensation using deprotonated azolium salts with strong Brønsted bases was reported after fifty years of its first observation. ${ }^{11}$

The aim of this document is to review relevant information related to the $N$-heterocyclic carbene catalysed self-condensation of benzaldehyde derivatives to prepare benzoins (1,2-diarylacyloines) when non-chiral ionic liquids derived from thiazolium and imidazolium salts are used. Several reviews including other types of reactions (mainly crossed and asymmetric versions) or with several different cations has been already reported. ${ }^{12-14}$

\section{Formation of $\mathbf{N}$-heterocyclic carbenes from Ionic liquids used as pre-catalysts in benzoin condensation}

The self-condensation of (hetero)aromatic aldehydes, including furfural and 2-thenaldehyde was performed at room temperature without any base (neither solvent) using 1-butyl-3-methylimidazolium tetrafluoroborate $\left(\left[\mathrm{Bmim}_{\mathrm{B}} \mathrm{BF}_{4}\right)\right.$ and 3-benzyl-5-(2-hydroxyethyl)4-methylthiazolium chloride $([\mathrm{Bhmt}] \mathrm{Cl})$ as pre-catalysts, through a cathodic monoelectronic reduction of the imidazolium (thiazolium) cation to form the catalytically active nucleophilic carbene (imidazolium-2-ylidene or thiazolium-2-ylidene); this novel alternative to prepare the active catalyst $\mathrm{NHC}$ avoids the normal use of a Brønsted base for deprotonation on the azolium salt. Using this galvanostatic control yields from moderate (32\%) to very high ( $92 \%)$ were obtained for the purified products..$^{15,16}$ The existence of NHC derived from $\{[\mathrm{Bmim}] \mathrm{AcO}\}$ was later determined at $120^{\circ} \mathrm{C}$ by cyclic voltammetry (Scheme 1). ${ }^{17}$

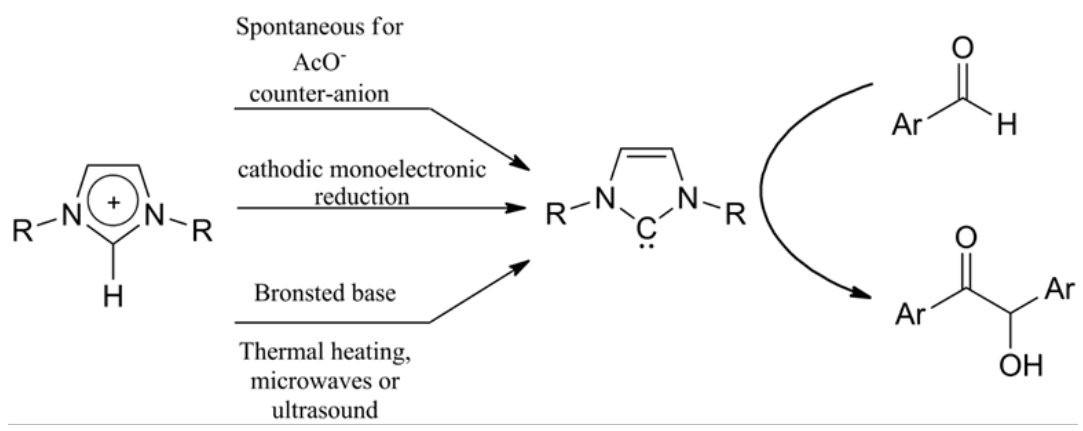

Scheme I Main methodologies for NHC formation from imidazolium cations. 
The spontaneous formation of a NHC derived from 1-ethyl-3methylimidazolium acetate $[\mathrm{Emim}] \mathrm{AcO}$ was determined to occur when the anisoin $\left(\mathrm{Ar}=p-\mathrm{MeOC}_{6} \mathrm{H}_{4}^{-}\right)$condensation isotopic effect of deuterium-C2 substituted [Emim] AcO was not observed. The kinetic data analysis showed that the rate determining step is the addition of the second aldehyde to the Breslow intermediate (formed from the carbene nucleophilic addition to the first aldehyde). The stepwise mechanism where the NHC is initially formed, and not the concerted addition to produce the Breslow intermediate, was also determined. ${ }^{18}$ This pre-catalytic effect on benzoin condensations was initially observed for ionic liquids formed from azolium cations with basic counter-anions (e.g. acetate) (Scheme 2)..$^{19}$
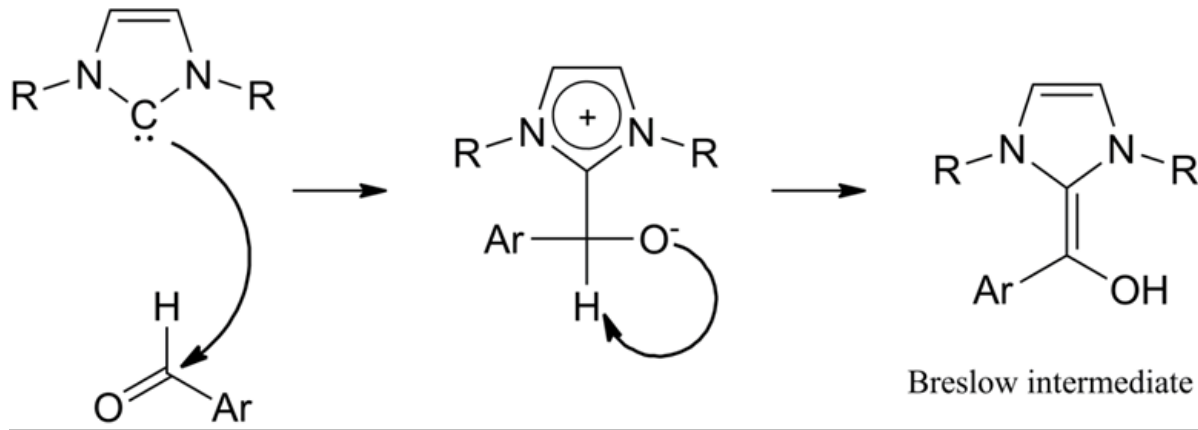

Breslow intermediate

Scheme 2 Breslow intermediate formation by nucleophilic addition of NHC to aromatic carboxaldehyde.

In the case of solvent free microwave assisted reactions using 1,8-diazabicyclo[5.4.0] undec-7-ene (DBU, $20 \mathrm{~mol} \%$ ) or sodium methoxide $(2 \mathrm{~mol} \%)$ as base, the ionic liquid counter-anion $\left(\mathrm{BF}_{4}, \mathrm{OTf}\right.$, $\mathrm{PF}_{6}, \mathrm{NTf}_{2}$ ) did not affect the catalysis, giving good reaction yields for the benzoin condensation. ${ }^{20,21}$ Similar condition and obtained yields were reported with low frequency $(30 \mathrm{kHz})$ ultrasonic irradiation..$^{22}$ Evidently, azolium cations with substituents in C2 cannot be used as catalysts. ${ }^{10}$ Substituents on the azolium ring have low influence in the catalyst, ${ }^{23}$ as in polymer supported poly(styrene)-co-poly(4vinylbenzylethylimidazolium) acetate [as homopolymer and statistical copolymer $] ;{ }^{24}$ when steric hindrance increase for di- and tri-azolium salts, the influence is notable an lower yields of the condensed products are obtained. ${ }^{10}$ Most of the reaction reviewed select THF, $\mathrm{MeOH}$ or solvent free conditions.

\section{Conclusion}

Seddon ${ }^{1 \S}$ and Plechkova are recognized authors in the field of ionic liquids who critically analyse the "labyrinth" of information about ionic liquids and their parallel use in research and industry. ${ }^{25}$ Thousands of journal articles have been written, and the information related to benzoin condensation using azolium salts as pre-catalysts is continually growing for this known model synthetic reaction. The use of inert atmosphere, temperature control and low catalyst charge in benzoin condensations are keys to avoid secondary reactions, mainly competitive oxidations (benzil formation, benzoyl and benzoic acid derivatives) or Cannizzaro's by-products.

\section{Funding details}

VIE-UIS Internal project 1870.

\section{Acknowledgements}

Authors express their acknowledgement to Dirección de Investigación y Extensión (DIEF) Faculty of Science, Vicerrectoría de Investigación (VIE)-Universidad Industrial de Santander (UIS).

\section{Conflict of interest}

Author declares that there is no conflict of interest.

I§ Kenneth Richard Seddon, Queen's University Belfast, UK (I950 - 2018), was a pioneer of ionic liquid research and green chemistry.

\section{References}

1. Welton T. Room-Temperature Ionic Liquids. Solvents for Synthesis and Catalysis. Chem Rev. 1999;99(8):2071-2083.

2. Wasserscheid P, Welton T. Ionic Liquids in Synthesis. Germany: Wiley$\mathrm{VCH} ; 2002$.

3. Enders D, Niemeier O, Henseler A. Organocatalysis by N-Heterocyclic Carbenes. Chem Rev. 2007;107(12):5606-5655.

4. Hopkinson MN, Richter C, Schedler M, et al. An overview of N-heterocyclic carbenes. Nature. 2014;510(7506):485-496.

5. Flanigan DM, Romanov-Michailidis F, White NA, et al. Organocatalytic Reactions Enabled by N-Heterocyclic Carbenes. Chem Rev. 2015;115(17):9307-9387.

6. Bugaut X, Glorius F. Organocatalytic umpolung: N-heterocyclic carbenes and beyond. Chem Soc Rev. 2012;41(9):3511.

7. Eymur S, Göllü M, Tanyeli C. Umpolung strategy: Advances in catalytic C-C bond formations. Turk J Chem. 2013;37:586-609.

8. Ukai T, Tanaka R, Dokawa S. A new catalyst for acyloin condensation. $J$ Pharm Soc Jpn. 1943;63(6):296-300.

9. Pavia DL, Lampman GM, Kriz GS, Engel RG. A Small-Scale Approach to Organic Laboratory Techniques. 3rd ed. Belmont: Brooks/Cole, Cengage Learning; 2011.

10. Gao G, Xiao R, Yuan Y, et al. Efficient imidazolium catalysts for the benzoin condensation. J Chem Res. 2002;2002(6):262-263.

11. Miyashita A, Suzuki Y, Iwamoto KI, et al. Catalytic Action of Azolium Salts. VI. Preparation of Benzoins and Acyloins by Condensation of Aldehydes Catalyzed by Azolium Salts. Chem Pharm Bull. 1994;42(12):2633-2635.

12. Menon RS, Biju AT, Nair V. Recent advances in N-heterocyclic carbene (NHC)-catalysed benzoin reactions. Beilstein J Org Chem. 2016;12:444461.

13. Ren Q, Li M, Yuan L, Wang J. Recent advances in N-heterocyclic carbene catalyzed achiral synthesis. Org Biomol Chem. 2017;15(22):4731-4749.

14. Gaggero N, Pandini S. Advances in chemoselective intermolecular cross-benzoin-type condensation reactions. Org Biomol Chem. 2017;15(33):6867-6887. 
15. Orsini $\mathrm{M}$, Chiarotto $\mathrm{I}$, Elinson $\mathrm{MN}$, et al. Benzoin condensation in 1,3-dialkylimidazolium ionic liquids via electrochemical generation of N-heterocyclic carbene. Electrochem Commun. 2009;11(5):1013-1017.

16. Chiarotto I, Feroci M, Orsini M, et al. Study on the Reactivity of Aldehydes in Electrolyzed Ionic Liquids: Benzoin Condensation Volatile Organic Compounds (VOCs) vs. Room Temperature Ionic Liquids (RTILs). Adv Synth Catal. 2010;352(18):3287-3292.

17. Chiarotto I, Feroci M, Inesi A. First direct evidence of N-heterocyclic carbene in BMIm acetate ionic liquid. An electrochemical and chemical study on the role of temperature. New J Chem. 2017;41(16):7840-7843.

18. Daud NMAN, Bakis E, Hallett JP, et al. Evidence for the spontaneous formation of $\mathrm{N}$-heterocyclic carbenes in imidazolium based ionic liquids. Chem Commun. 2017;53(81):11154-11156.

19. Kelemen Z, Hollóczki O, Nagy J, et al. An organocatalytic ionic liquid. Org Biomol Chem. 2011;9(15):5362-5364.

20. Estager J, Lévêque J-M, Turgis R, Draye M. Solventless and swift benzoin condensation catalyzed by 1-alkyl-3-methylimidazolium ionic liquids under microwave irradiation. J Mol Cat A-Chem. 2006;256(12):261-264
21. Aupoix A, Pégot B, Vo-Thanh G. Synthesis of imidazolium and pyridinium-based ionic liquids and application of 1-alkyl-3methylimidazolium salts as pre-catalysts for the benzoin condensation using solvent-free and microwave activation. Tetrahedron. 2010;66(6):1352-1356.

22. Estager J, Lévêque JM, Turgis R, et al. Neat benzoin condensation in recyclable room-temperature ionic liquids under ultrasonic activation. Tetrahedron Lett. 2007;48(5):755-759.

23. Karimian K, Mohanazadeh F, Rezai S. Application of Polymer-Bound Thiazolium salts to the Synthesis of Acyloins and Benzoins: Effects of Solvent and Substituents of the Thiazolium Nucleus. J Heterocycl Chem. 1983;20(4):1119-1121.

24. Lambert R, Coupillaud P, Wirotius A-L, et al. Imidazolium-Based Poly(Ionic Liquid)s Featuring Acetate Counter Anions: Thermally Latent and Recyclable Precursors of Polymer-Supported $N$ -Heterocyclic Carbenes for Organocatalysis. Macromol Rapid Commun. 2016;37(14):1143-1149.

25. Plechkova NV, Seddon KR. Applications of ionic liquids in the chemical industry. Chem Soc Rev. 2008;37(1):123-150. 